Indian Journal of Science and Technology

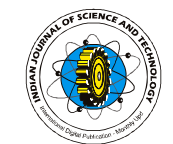

Vol.2 No. 8 (Aug 2009)

ISSN: 0974- 6846

\title{
Assessment of proliferative index and its association with Ki-67 antigen molecule expression in nodular hyperplasia of prostate
}

\author{
Srikumar Chakravarthi ${ }^{1}$, P. Thanikachalam ${ }^{1}$, H.S. Nagaraja ${ }^{2}$, David Low Wee Yang and Nadeem Irfan Bukhari ${ }^{3}$ \\ ${ }_{1}^{1}$ Department of Pathology; ${ }^{2}$ Department of Physiology, Faculty of Medicine; ${ }^{3}$ Faculty of Pharmacy; International \\ Medical University, Bukit Jalil, 57000 Kuala Lumpur, Malaysia \\ srikumar_chakravarthi@imu.edu.my
}

Abstract: The cytoplasmic expression of Ki-67, a nuclear protein that appears primarily during the proliferative phases of the cell cycle was studied in benign tumours of the prostate gland. Archival prostatic tissue from 39 patients with nodular hyperplasia and no prior or subsequent prostatic carcinoma that have been obtained through transurethral prostatectomy (TURP) procedure, were used in this study. The proliferative index was assessed by calculating the number of actively proliferating cells in the H\&E sections in varied histologic patterns like hyperplastic epithelium, proliferating stroma, normal glands and normal stroma. The nuclear protein Ki67 was analyzed by immunohistochemistry for determining the cytoplasmic positivity of the tumour cells. The proliferative index in the hyperplastic tissues was higher, indicating an increased activity of cellular proliferation, compared with the normal tissues, which was highly significant $(p<0.01)$. Out of 39 cases of prostatic tissue, 25 (64\%) showed positivity for Ki-67 expression. Pearson's correlation test was applied to and showed significant association $(p<0.05)$ between the intensity of Ki-67 expression with proliferative index. Comparisons of proliferative indices between the normal cells and tumour cells showed significant correlation, strongly suggesting the higher cell proliferation in the benign lesions. Enhanced expression of $\mathrm{Ki}-67$ by the tumour cells suggests a growth imbalance in favour of cell proliferation that might ultimately promote prostatic hyperplasia.

Keywords: prostate, mitosis, Ki-67, nodular hyperplasia.

\section{Introduction}

Benign prostatic hyperplasia $(\mathrm{BPH})$, a relatively common disease, is caused by the excess proliferation of prostatic stroma and glands. The resultant prostate gland enlargement is a cause of many lower urinary tract symptoms which decrease the quality of life, particulary for ageing males ( $>40$ years) (Robbins \& Cotran, 2005). It is believed that worldwide 30 million men have symptoms due to this benign enlargement (Barry \& O'Leary, 1995). The aetiology of this disease still remains unclear, though there is evidence pointing to the relationship between the levels of male hormones and their metabolites and the onset of prostatic hyperplasia (Trachtenberg et al., 1980). Like any other organ in the human body, the size of prostate is maintained by a delicate balance between apoptosis and mitosis. Therefore any imbalance of mitosis over apoptosis would lead to an increase in organ size (Kyprianou et al., 1996).

$\mathrm{Ki}-67$ is a nuclear protein that is related to the proliferative phase of the cell cycle (Key et al., 1994). This protein is detected exclusively within the nucleus during the interphase (G0). However during mitosis it is relocated to the surface of chromosomes. It is present during all the active phases of the cell cycle (G1, S, G2 and $M$ phases) but absent during G0. This makes it an excellent marker for the detection of cell proliferation (Schlüter et al., 1993). The over-expression of Ki-67 would therefore suggest an increase in mitotic activity of the prostatic cells.

The objectives of this study are to observe the cytoplasmic expression of the mitotic regulatory protein, Ki-67 in benign nodular hyperplasia of prostate in histopathological sections by immunohistochemical staining, and to demonstrate that the increase of cell proliferation activity is an important regulatory mechanism in benign tumours of prostate, by calculating the proliferative index in the histopathological sections. Subsequently, to compare Ki-67 index of hyperplastic tissues with that of the normal tissues to assess for the proliferative potential of the tumour.

Materials and methods

Archival paraffin-embedded prostatic tissue from 39 patients with nodular hyperplasia were obtained from Hospital Seremban after proper informed consent from the patients, and due approval from the IMU Joint Research and Ethical committee after prior submission of research protocol (Research grant I-01-2007/07). The tissue was obtained through transurethral prostatectomy (TURP) procedure that was done on the patients. All patients were of Malaysian origin, and aged between 55 and 73 years old $(64.67 \pm 5.24)$. The inclusion criteria were nodular hyperplasia per se, which have been confirmed by high PSA levels, and per rectal digital examination. Hyperplasia associated with inflammation, suggesting prostatitis, and/ or associated urinary tract infections, and carcinoma prostate were excluded, so as to avoid deviation in the hypothesis of the present study. The normal healthy tissues were obtained as comparison from the same patients. During the TURP, few chips of the healthy prostate tissue from the deeper, more peripheral zone were also removed and then embedded in the same blocks as the nodular areas. These tissues were used as the control in this project. The bits of prostate tissue were fixed in formalin, and processed through alcohol, acetone and xylene. Blocks of tissue were subsequently prepared using paraffin wax and sections of $4 \mu \mathrm{m}$ on silanized slides were taken from the blocks using a rotary microtome.

Research article

(c)Indian Society for Education and Environment (iSee)
"Prostatic hyperplasia \& Ki-67" http://www.indjst.org
Chakravarthi et al. Indian J.Sci.Technol. 
For Haematoxylin \& Eosin staining, the slides were dewaxed in a hot air oven at $59.5^{\circ} \mathrm{C}$ for 30 minutes followed by two changes of xylene for 1 minute each and 3 changes of alcohol at 30 seconds each. The slides were then immersed in tap water to render it aqueous. The slides were then stained with haematoxylin and eosin, and mounted with coverslips using Vectamount mounting media. Immunohistochemistry staining

The slides were dewaxed for 45 minutes in a hot air oven at $59.5^{\circ} \mathrm{C}$, and passed through xylene and decreasing concentrations of alcohol (abosolute alcohol, 90\%, 80\% $70 \%)$ to distilled water at $4 \mathrm{~min}$ intervals each. Target retrieval was done by placing the sections in target retrieval solution at $95^{\circ} \mathrm{C}$ for about 45 minutes in a hot water bath, and then cooled to room temperature for another 20 minutes. The slides were rinsed with Tris Buffer Saline solution and soaked in it for 10 minutes. Dual endogenous enzyme block was applied on the specimens for 20 minutes. The slides were again rinsed with TBS and excess buffer was carefully wiped off.

Monoclonal mouse antihuman ki-67 (primary antibody) (M724001, Clone MIB-1, $1 \mathrm{~mL}$ ) purchased from DAKO Cytomation, Denmark (IHC Kit from Bita Lifescience, Malaysia), diluted in 1:50 ratio (as recommended), was incubated for $90 \mathrm{~min}$ at room temperature. Dako kit Antibody diluent with background reducing components solution (provided with primary antibody) was used as the diluent. Labelled polymer HRP was applied on the slides for 40 min before soaking them in TBS for 5 minutes. This was then rinsed with TBS and buffered for another $5 \mathrm{~min}$. Substratechromogen, diluted in 1:50 ratio, $(10 \mu \mathrm{L}$ of $\mathrm{DAB}+$ chromogen was added to $500 \mu \mathrm{L}$ of DAB+ substrate buffer and was shaken thoroughly) was added at room temperature for $20 \mathrm{~min}$. The slides were then carefully rinsed with distilled water, and counterstained with haematoxylin ( 2 minutes), and then rinsed 5 seconds with blueing agent, following that rinsed with water and
Vol.2 No. 8 (Aug 2009)

ISSN: 0974- 6846

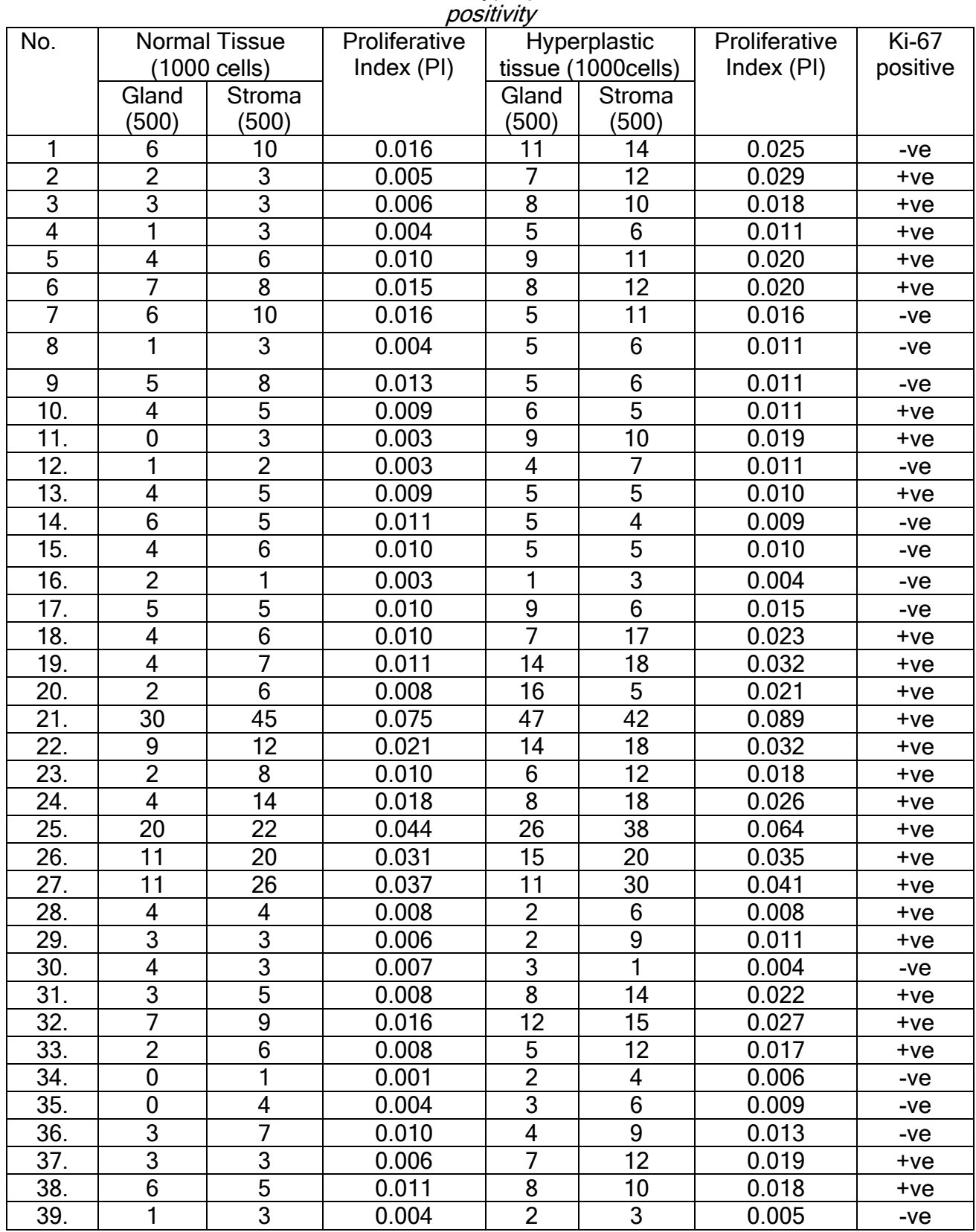

normal tissues is 0.013, and for hyperplastic tissues is 0.02 mounted with coverslip with vecta mounting media after being air dryed.

For the tissues that were stained with Haeamatoxylin and eosin, the proliferative index was calculated by observing the number of mitotic cells in the glands and stroma of tissues out of 1000 cells. The mitotic cells were recognized by of each of the various morphological features that the cell nuclei undergo during the various phases of mitosis. The counting of the mitotic cells was done for 500 cells for each group of glandular tissue and stromal tissue in the normal and hyperplastic tissue. The proliferative index $(\mathrm{PI})$ was calculated as the number of mitotic activity in a total of 1000 cells.
Research article

CIndian Society for Education and Environment (iSee)
"Prostatic hyperplasia \& Ki-67" http://www.indjst.org
Chakravarthi et al. Indian J.Sci.Technol. 


\section{Statistical analysis}

For the correlation between $\mathrm{PI}$ of normal tissue to Ki-67 positivity and $\mathrm{PI}$ of hyperplastic tissues to $\mathrm{KI}-67$ positivity, Pearson's test and Wilcoxon rank test were employed. For analysing normal distribution of data Spearman's test and Kolgomorov Smirnov test were used. A $p>0.05$ was taken as normal distribution of data. In this study, the following were compared:

I. Normal gland versus Hyperplastic gland

II. Normal stroma versus Hyperplastic stroma

III. Normal proliferative index versus Hyperplastic proliferative index

While correlation was determined between the following:

IV. The correlation between Hyperplastic proliferative index and Ki-67 positivity

$\mathrm{V}$. The correlation between Normal proliferative index and Ki-67 positivity

VI. The correlation between Ki-67 positivity for various age groups

Table 3. PI Correlation of tissues to Ki-67 positivity

\begin{tabular}{|c|c|c|c|}
\hline Correlation & $\mathrm{R}^{2}$ & $\mathrm{P}$ value & Significance \\
\hline $\begin{array}{c}\text { PI hyperplastic tissue } \\
\text { to Ki-67 positivity }\end{array}$ & 0.619 & 0.000 & $\begin{array}{c}\text { YES } \\
(\mathrm{p}<0.05)\end{array}$ \\
\hline $\begin{array}{c}\text { PI normal tissue to } \\
\text { KI-67 positivity }\end{array}$ & 0.253 & 0.119 & $\begin{array}{c}\mathrm{NO} \\
(\mathrm{p}>0.05)\end{array}$ \\
\hline
\end{tabular}

For statistical analysis, the data was explored using Kolgomorov Smirnov test for distribution of the data. A $p>0.05$ was taken as normal distribution of data. If data is normally distributed, pairseel test will be employed to compare studies I, II and III. Otherwise, Wilcoxon test will be used. A $p$ value less than 0.05 was taken as significant.

Results

The Proliferative index $(\mathrm{PI})$ of normal and hyperplastic tissues and their relation to $\mathrm{Ki}-67$ positivity is provided in Table 1 . The mean $\mathrm{PI}$ for normal tissues is 0.013 , and for hyperplastic tissues is 0.020 . Results of the Kolgomorov Smirnov test on distribution of data (Table 2) showed that the distribution was skewed and not normally distributed. Thus, Wilcoxon rank test was used (Table 4) for comparison.

The Study I of PI between normal gland $(0.010)$ versus that of the hyperplastic gland $(0.017)$ was highly significant $p=0.00(p<0.01)$ (Table 3$)$.

Study II, the difference of proliferative index between normal stroma $(0.012)$ versus that of hyperplastic stroma
Vol.2 No. 8 (Aug 2009)

ISSN: 0974- 6846
Table 2. Results of the Kolgomorov

Smirnov test on distribution of data

Table 4. Results of Wilcoxon
rank test
\begin{tabular}{|c|c|c|}
\hline Study & $\begin{array}{c}\text { P Value } \\
\text { Wilcoxon } \\
\text { Rank Test }\end{array}$ & Z Value \\
\hline I & $0.00{ }^{*}$ & -4.719 \\
\hline II & $0.00{ }^{*}$ & -4.520 \\
\hline III & $0.00{ }^{*}$ & -49.60 \\
\hline *Significant difference at $p<0.01$
\end{tabular}

Fig. 1. Ki-67 positivity for various age groups


Discussion hyperplasia
(0.023) was highly significant $p=0.00$ $(P<0.01)$, and significantly raised in older age groups, $p=0.00(p<0.05)$.

Study III, the difference between PI of hyperplastic tissue (0.020) and the PI of normal tissue (0.013) was highly significant, $\quad p=0.00 \quad(p<0.05) \quad$ and significantly raised in older age groups, $p=0.01(p<0.05)$.

\section{Correlation of Proliferative index to Ki-67 positivity}

For the correlation between $\mathrm{PI}$ of normal tissue to $\mathrm{Ki}$ 67 positivity and $\mathrm{PI}$ of hyperplastic tissues to $\mathrm{KI}-67$ positivity, Pearson's or Spearman's test was employed, respectivley depending upon whether data in distributed normally or not (Fig.1; Table 4). A p value less than 0.05 was taken as significant.

In this study, the data was not normally distributed; therefore Spearman's test was employed.

Spearman's correlation test indicated that $\mathrm{PI}$ of hyperplastic tissues $(0.020)$ is significantly correlated to $\mathrm{Ki}-67$ positivity while $\mathrm{PI}$ for normal tissue is not correlated.

Proliferative index (Mitosis) and benign prostatic

Benign prostatic hyperplasia is due to excessive cellular growth of both the glandular and the stromal elements of the gland. There are theories suggesting that ageing and hormonal factors are central to the development of $\mathrm{BPH}$. Androgens, especially dihydrotestosterone (DHT), stimulate cell proliferation activity and inhibit cell death (Wright et al., 1996). The present study has focused on mitosis and the factor related to mitosis (the nuclear protein Ki-67).

In every human being, about a hundred thousand cells are produced every second by mitosis and a similar number die by apoptosis. It is therefore crucial that the balance between cell death and proliferation is tightly regulated (Jacobson et al., 1997).

The study examined the incidence of mitosis cells in human $\mathrm{BPH}$, establishing its significance in regulating the dynamics of prostate growth. Also it examined the relationship between ki-67 and incidence of mitosis as proliferative index (PI). The present finding shows that the $\mathrm{PI}$ of the tumour was significantly higher than that of the normal tissues. Low PI in normal tissues results in the maintenance of the normal size of the prostate, which is consistent with previous studies (Kyprianou et al.,1996). However, in BPH tissues,
Research article

CIndian Society for Education and Environment (iSee)
"Prostatic hyperplasia \& Ki-67" http://www.indjst.org
Chakravarthi et al. Indian J.Sci.Technol. 
the reverse was observed, with a significantly higher proliferative index, thus proving the resistance to apoptosis and increase in mitosis (Jefferson et al., 2000) that resulted in benign prostatic hyperplasia.

Ki-67, and its association with mitosis and benign prostatic hyperplasia

$\mathrm{BPH}$ seems to stem from the imbalance between the cell proliferation and cell death. In this study, slides of BPH tissues were stained using immunohistochemistry staining, and the expression of $\mathrm{Ki}-67$ was observed (Fig. 2-4). Slides that were positive for Ki-67 expression were then marked as + and those were negative for $\mathrm{Ki}$ 67 was marked as 0. Interestingly, Tamboli et al. (1996) and Kyprianou et al. (1996) arrived with similar findings that the mean $\mathrm{Ki}-67$ antigen expression significantly increases in hyperplastic glands when compared to normal.

We found that out of $39 \mathrm{BPH}$ tissue stained by immunohistochemistry, 25 (64\%) showed positivity for Ki-67 expression. There was significant correlation between the intensity of Ki-67 expression with mitosis. This proved our theory that Ki-67 regulates cell mitosis up to certain extent. Hence, the result present here supports the theory that with an increase of ki-67 level, there was an increase in mitosis, which eventually leads to enlargement of the organ.

\section{References}

1. Barry MJ and O'Leary MP (1995) Advances in benign prostatic hyperplasia: The developmental and clinical utility of symptom scores. Urol. Clin. North Am. 22(2), 299-307.

2. Jacobson M, Weil $M$ and Raff MC (1997) Programmed cell death in animal development. Cell. 88, 347-354.

3. Jefferson KP, Persad RA and Holly JMP (2000) Apoptosis and its relevant to urologist. BJU International. 86, 598-606.
Fig.2. Photomicrograph of benign prostatic hyperplasia tissue stained with immunohistochemistry for Ki-67, showing positive glandular staining at $400 X$ (IHC with Ki-67, original magnification $\times 1000$ )

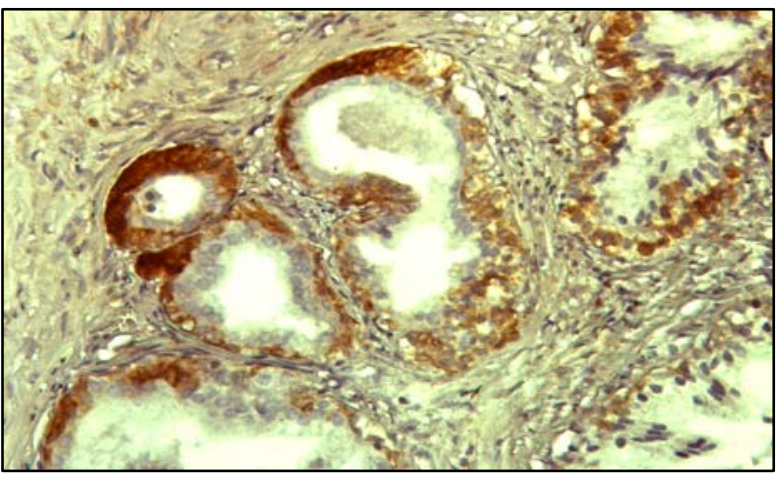

Fig. 3. Photomicrograph of diffuse glandular expression of Ki-67 (IHC with Ki-67, original magnification x 1000)

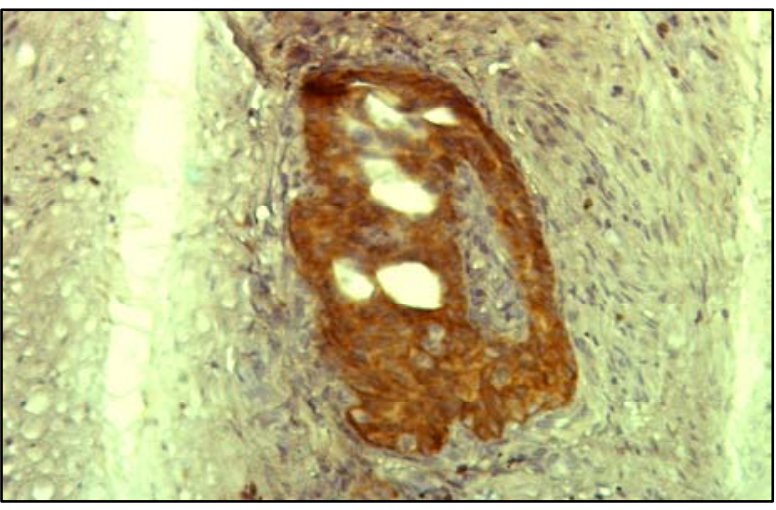

Fig.4. Photomicrograph of benign prostatic hyperplasia, showing cells undergoing mitosis (arrows) in the gland and stroma. (H\&E, original magnification $\times 1000$ )

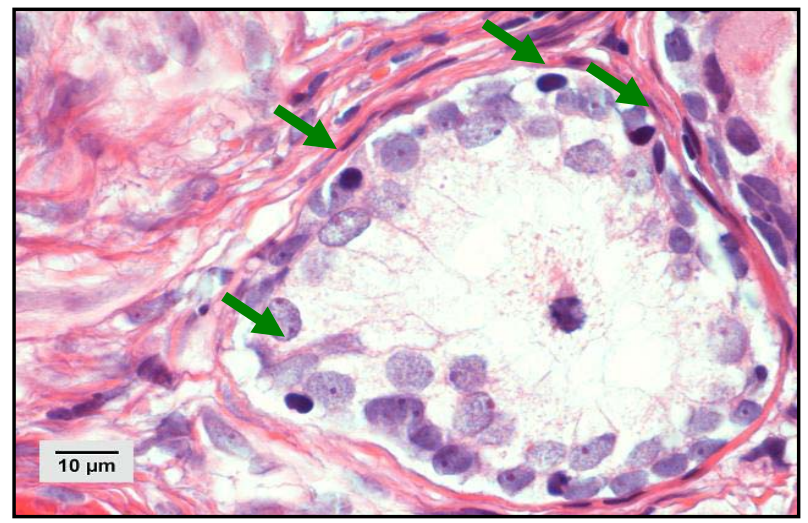

4. Key G, Kubbutat MH and Gerdes J (1994) Assessment of cell proliferation by means of an enzyme- linked immunosorbent assay based on the detection of the Ki-67 protein. J. Immunol. Methods. 28, 177(1-2), 113-117.

5. Kyprianou N, Tu HC and Stephen C (1996) Apoptotic versus proliferative activities in human benign prostatic hyperplasia. Human Pathology. 27(7), 668675.

6. Robbins SL and Cotran K (2005) Pathological basis of disease. 7th Ed. Elsevier, The Netherlands. $\quad 7(21)$, 1048-1050.

7. Schlüter $C$, Duchrow $M$, Wohlenberg C, Becker $\mathrm{MH}$, Key G, Flad HD and Gerdes J (1993) The cell proliferation-associated antigen of antibody Ki67: a very large, ubiquitous nuclear protein with numerous repeated elements, representing a new kind of cell cycle-maintaining proteins. J. Cell Biol. 123(3), 513-522.

8. Tamboli $\mathrm{P}$, Amin MB, Schultz DS, Linden $M$ and Kubus J (1996) Comparative analysis of the nuclear proliferative index in benign prostate, prostatic intraepithelial neoplasia, and prostatic carcinoma. Mod. Pathol. 9(10), 1015-1019.

9. Trachtenberg J, Hicks LL and Walsh PC (1980) Androgen- and estrogen-receptor content in spontaneous and experimentally induced canine prostatic hyperplasia. J. Clin. Invest. 65, I05I-1059.

10. Wright AS, Thomas LN, Douglas RC., et.al. (1996) Relative potency of testosterone and dihydrotestosterone in preventing atrophy and apoptosis in the prostate of the castrated rat. J. Clin. Invest. 98(11), 2558-2563.
Research article

(C)Indian Society for Education and Environment (iSee)
"Prostatic hyperplasia \& Ki-67" http://www.indjst.org
Chakravarthi et al. Indian J.Sci.Technol. 